\title{
Joining Alumina to Inconel 600 and UMCo-50 Superalloys Using an Sn10Ag4Ti Active Filler Metal
}

\author{
S.Y. Chang, Y.T. Hung, and T.H. Chuang
}

(Submitted 13 November 2002)

\begin{abstract}
Alumina ceramics were brazed to Inconel 600 and UMCo-50 superalloys at $900{ }^{\circ} \mathrm{C}$ for 10 min using an Sn10Ag4Ti active filler metal. The brazing filler showed good wettability on alumina and superalloys. The flexural strengths were 69 and $57 \mathrm{MPa}$ for alumina/Inconel 600 and alumina/UMCo-50 joints, respectively. In both cases, the brazed specimens fractured along the Sn10Ag4Ti/superalloy interfaces after four-point bending tests. Electron probe microanalysis (EPMA) elemental mapping revealed that the Ni of Inconel 600 and the Co of UMCo-50 dissolved into Sn10Ag4Ti filler metal, which serves to reinforce the weak Sn10Ag4Ti matrix.
\end{abstract}

Keywords active filler metal, alumina ceramic, brazing, Cobase superalloy, Ni-base superalloy

\section{Introduction}

Ni-based Inconel 600 and Co-based UMCo-50 superalloys are widely used in the petroleum industry as an oil-oxygen burner material. However, the tip of such a superalloy burner has been found to erode severely due to high-speed blowing of the particles, leading to a shorter lifespan for the operation. A solution has been proposed to replace the material for use in the burner tip with alumina ceramic to be bonded with the superalloy burner. Since the area of ceramic/metal bonding is cooled well to a sufficiently low temperature, the brazing method is ideal for the purpose delineated above. ${ }^{[1,2]}$

For the brazing of ceramic to ceramic, or to metal, Ag-Cu$\mathrm{Ti}$ alloy is the most popular filler metal. ${ }^{[3-7]}$ In a previous study, alumina ceramics have been brazed with alumina, Inconel 600 , and UMCo-50 using an Ag26Cu8Ti filler metal. ${ }^{[1]}$ The results indicated that the bonding strengths of alumina brazed with both superalloys were much lower than those of the alumina/ alumina joint. Fractography showed that in the case of alumina/

S.Y. Chang, Y.T. Hung, and T.H. Chuang, Department of Materials Science and Engineering, National Taiwan University, Taipei, Taiwan. Contact e-mail: tunghan@ccms.ntu.edu.tw.

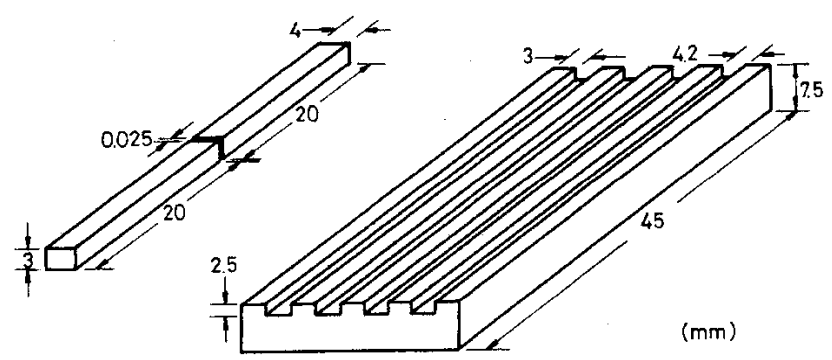

Fig. 1 Size and geometry of ceramic/filler metal/superalloy specimen assembly and brazing holder alumina joining, fracture occurred along the filler metal after the four-point bending test. In contrast, for the brazement of alumina with both superalloys, fracture was observed mostly in the ceramic. ${ }^{[1]}$ This phenomenon was attributed to the large difference in thermal expansion coefficients between alumina ceramic and superalloy, which caused severe thermal stress during the cooling stage of the brazing process. To solve this problem, a low-melting-point filler metal Sn10Ag4Ti is adopted here. ${ }^{[8]}$ Although the act of brazing with Sn10Ag4Ti must also be conducted at temperatures above $850{ }^{\circ} \mathrm{C}$ (similar to the case using the traditional $\mathrm{Ag}-\mathrm{Cu}-\mathrm{Ti}$ active filler metal), the thermal stress can be alleviated by its lower solidification temperature $\left(221-300{ }^{\circ} \mathrm{C}\right) .{ }^{[9]}$

\section{Experimental}

The chemical compositions and mechanical properties of Inconel 600 and UMCo-50 superalloys used in this study are given in Tables 1 and 2 . The bulk alumina ceramic was fabricated by pressure casting and sintered at $1600{ }^{\circ} \mathrm{C}$ for $2 \mathrm{~h}$ after

Table 1 Chemical Compositions of Inconel 600 and UMCo-50, Superalloys Used in This Study

\begin{tabular}{lccrrrrr}
\hline & Ni & Co & Fe & Cr & C & Mn & Si \\
\hline Inconel 600 & 76.0 & $\ldots$ & 8.0 & 15.5 & 0.08 & 0.5 & 0.2 \\
UMCo-50 & $\ldots$ & 49.0 & 21.0 & 28.0 & 0.12 & $\ldots$ & $\ldots$ \\
\hline
\end{tabular}

Table 2 Mechanical Properties of Inconel 600, UMCo-50, and Alumina Ceramic Used in This Study

\begin{tabular}{lccccc}
\hline & $\begin{array}{c}\text { Melting } \\
\text { Temper- } \\
\text { ature, } \\
{ }^{\circ} \mathbf{C}\end{array}$ & $\begin{array}{c}\text { Coefficient } \\
\text { Density, } \\
\mathbf{M g} / \mathbf{m}^{\mathbf{3}}\end{array}$ & $\begin{array}{c}\text { of Thermal } \\
\text { Expansion, } \\
\mathbf{1 0}^{-\mathbf{6}} \mathbf{K}^{-\mathbf{1}}\end{array}$ & $\begin{array}{c}\text { Strength, } \\
\mathbf{M P a}\end{array}$ & $\begin{array}{c}\text { Young's } \\
\text { Modulus, } \\
\mathbf{G P a}\end{array}$ \\
\hline Inconel 600 & $1380-1395$ & 8.05 & 15.0 & 621 & 210 \\
UMCo-50 & $1355-1415$ & 8.42 & 14.9 & 745 & 215 \\
Alumina & 2050 & 3.94 & 7.9 & 384 & 388 \\
\hline
\end{tabular}




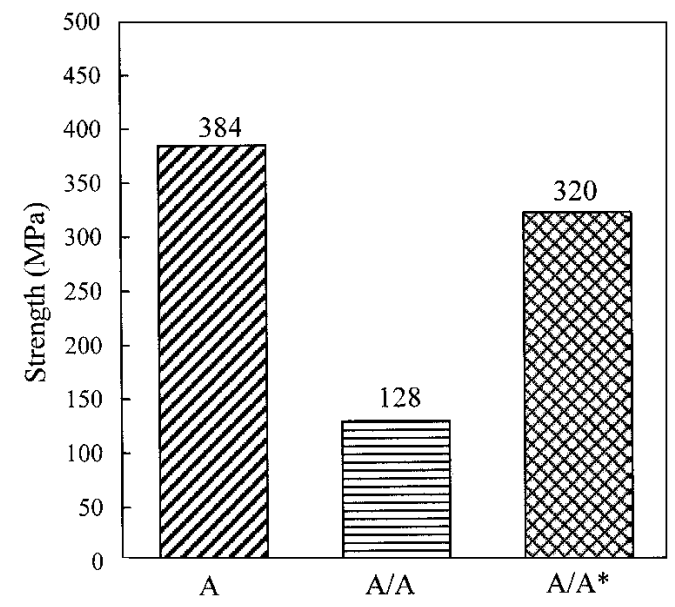

Fig. 2 Strength of alumina (A) and the bonding strengths of alumina brazed with alumina using an Sn10Ag4Ti (A/A) filler metal in this study and an $\mathrm{Ag} 26 \mathrm{Cu} 8 \mathrm{Ti}\left(\mathrm{A} / \mathrm{A}^{*}\right)$ filler metal in a previous study ${ }^{[1]}$ for comparison
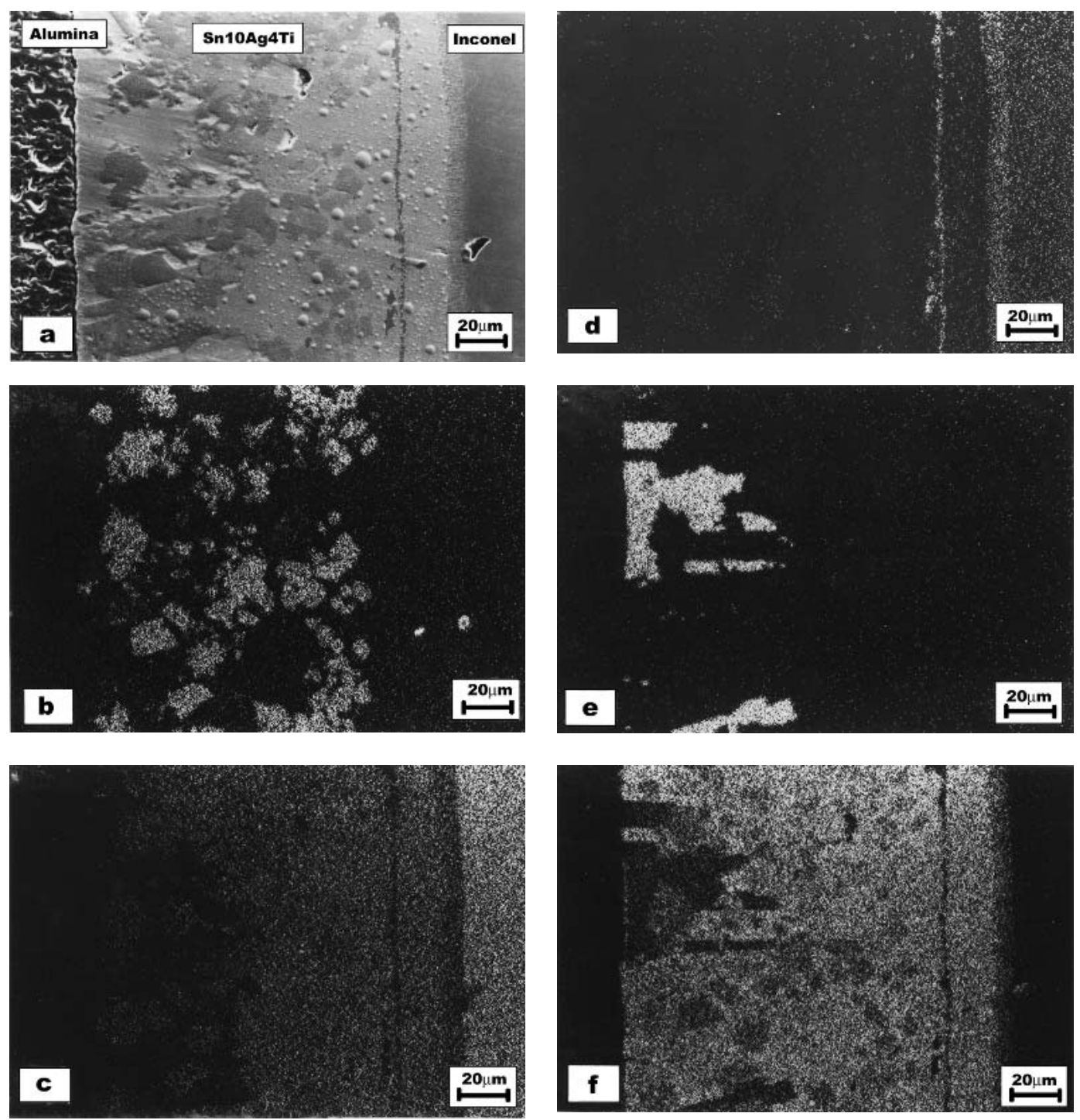

Fig. 4 Micrograph and EPMA analyses for the $\mathrm{Al}_{2} \mathrm{O}_{3} / \mathrm{Sn} 10 \mathrm{Ag} 4 \mathrm{Ti} / \mathrm{Inconel} 600$ joint after brazing at $900{ }^{\circ} \mathrm{C}$ for $10 \mathrm{~min}$. (a) interfacial microstructure; (b-f) elemental mappings for $\mathrm{Ti}, \mathrm{Ni}, \mathrm{Cr}, \mathrm{Ag}$, and $\mathrm{Sn}$, respectively

Fig. 3 Bonding strengths of alumina ceramics brazed with Inconel $600(\mathrm{~A} / \mathrm{I})$ and UMCo-50 (A/U) using Sn10Ag4Ti filler metal. For comparison, the previous results ${ }^{[1]}\left(\mathrm{A} / \mathrm{I}^{*}\right.$ and $\left.\mathrm{A} / \mathrm{U}^{*}\right)$ using an Ag26Cu8Ti filler metal are also shown.
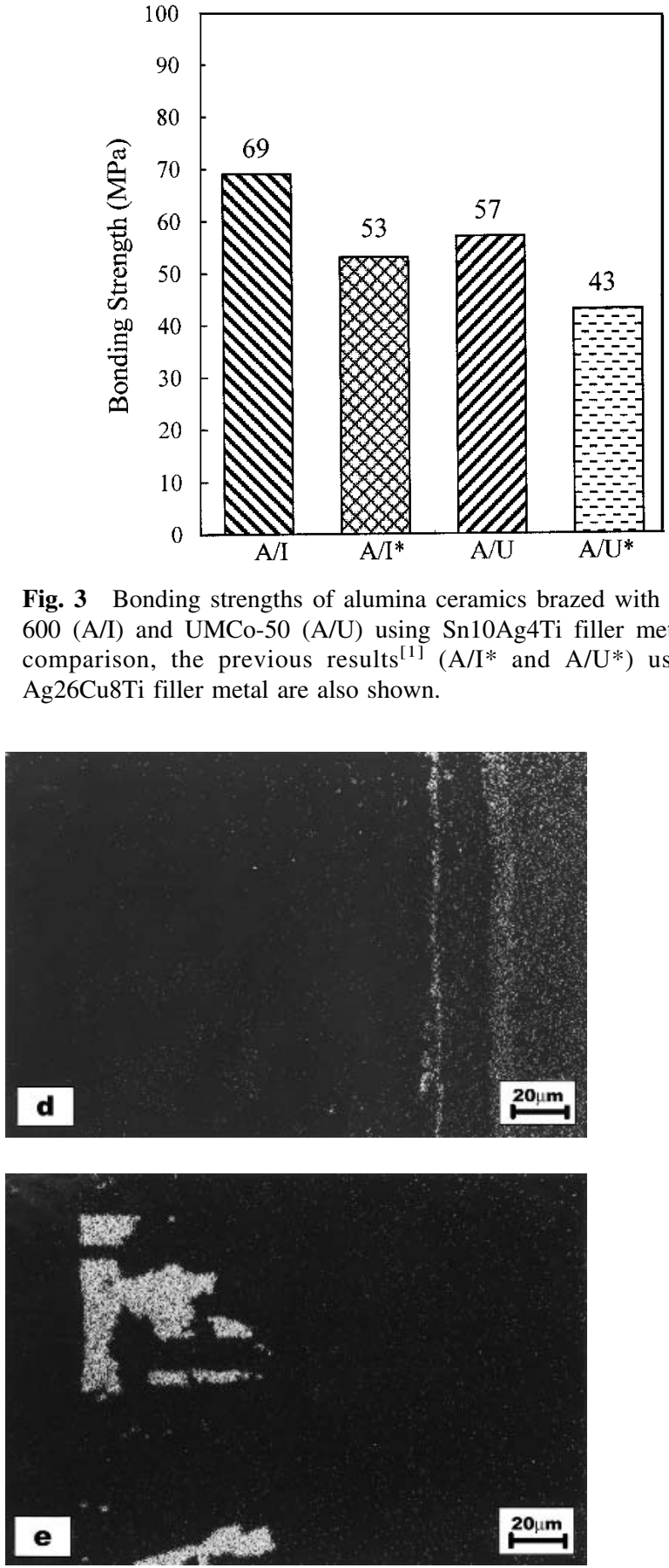

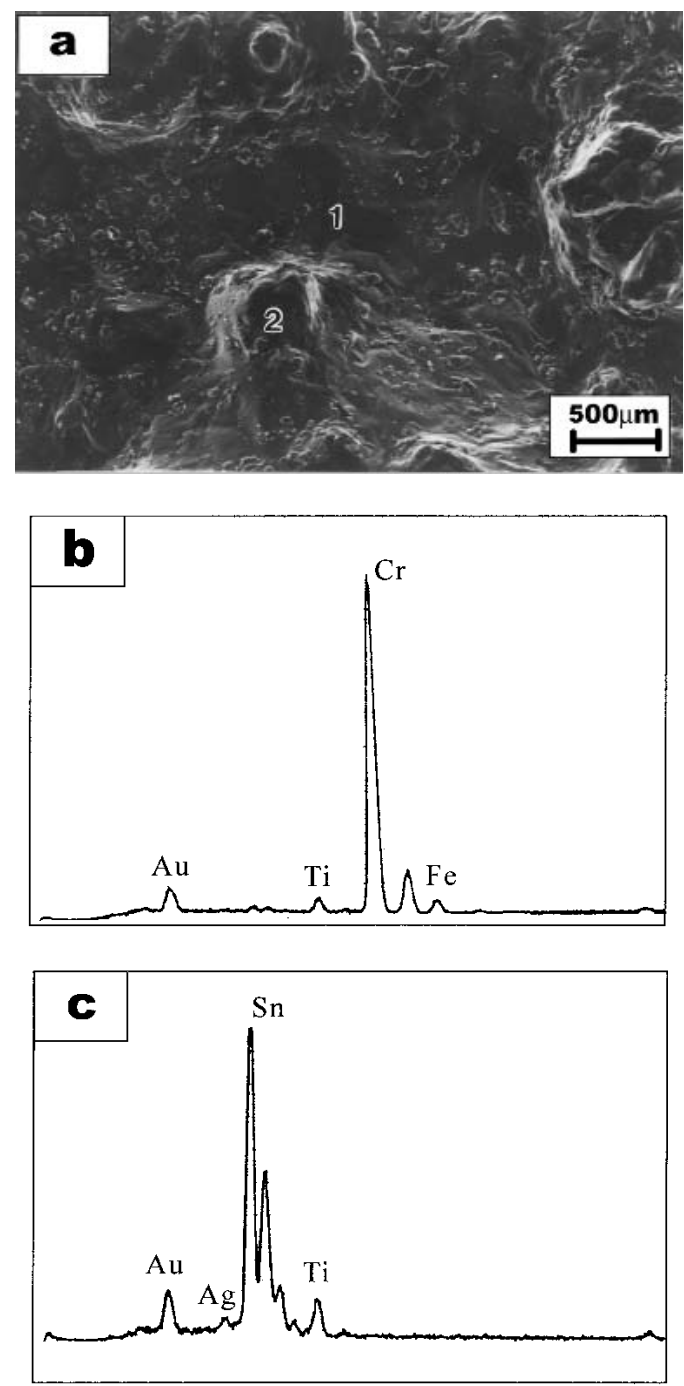

Fig. 5 EDX analysis on the fractured surface of the Alumina/Inconel 600 joint brazed with Sn10Ag4Ti filler metal. (a) fractography; (b) EDX peaks at point 1; (c) EDX peaks at point 2

24-h drying at $60{ }^{\circ} \mathrm{C}$. The mechanical properties of the alumina specimens are also given in Table 2. The active filler Sn10Ag4Ti (0.025 mm in thickness), which possessed a melting range (liquidus and solidus) between $221-300{ }^{\circ} \mathrm{C}$, was supplied by the Degussa Co., Hanau, Germany. The tensile strength of the filler metal was about $57 \mathrm{MPa}$.

For the brazing experiments, all the specimens with dimensions $3 \mathrm{~mm} \times 4 \mathrm{~mm} \times 20 \mathrm{~mm}$ were cut from the bulk plate using a diamond saw. Their surfaces were wet ground with $\mathrm{SiC}$ paper down to grade 1200 and polished with diamond paste to an arithmetical average roughness $(\mathrm{Ra})$ of $0.3 \mu \mathrm{m}$. The ceramic/superalloy assemblies with the active filler inserted in between were then placed into a fixture as shown in Fig. 1. Brazing was conducted at $900{ }^{\circ} \mathrm{C}$ for $10 \mathrm{~min}$ in a resistance furnace under a vacuum of approximately $10^{-4}$ torr. The strengths of the joints were characterized by four-point bending tests at an upper span of $10 \mathrm{~mm}$ and a lower span of $30 \mathrm{~mm}$. The crosshead speed was $0.1 \mathrm{~mm} / \mathrm{min}$. Five specimens were used for each brazing condition, and the average bonding strength was taken. To investigate the bonding mechanism and related interfacial reactions, the microstructure and composition of the joints were analyzed using an electron probe microanalyzer (EPMA), as well as a scanning electron microscope (SEM) equipped with energy dispersive $\mathrm{x}$-ray spectroscopy (EDX).

\section{Results and Discussion}

For the similar brazing of alumina to alumina using Sn10Ag4Ti filler metal, four-point bending tests give a bonding strength of $128 \mathrm{MPa}$ as shown in Fig. 2, which is much lower than the typical strength of alumina (384 MPa). Figure 2 also indicates that the brazement with Sn10Ag4Ti filler metal features a much lower bonding strength than a previous result $^{[1]}$ of alumina/alumina joint brazed with Ag26Cu8Ti (320 $\mathrm{MPa}$ ), which is attributed to the weaker matrix material of Sn10Ag4Ti.

For the dissimilar brazing of alumina to Inconel 600 superalloy using the same Sn10Ag4Ti filler metal, the bonding strength is increased from 53 to $69 \mathrm{MPa}$ compared with the result from a previous study ${ }^{[1]}$ using $\mathrm{Ag} 26 \mathrm{Cu} 8 \mathrm{Ti}$ (Fig. 3). EMPA analyses show that the Ti element clusters together inside of the Sn10Ag4Ti filler metal after brazing (Fig. 4b). In active brazing of the ceramic material, titanium is often found to segregate at the ceramic/filler metal interface. Although this phenomenon cannot be observed in Fig. 4(b), the Ti clusters show a tendency to disperse toward the alumina side. From Fig. 4(c) and (d), two distinct Cr-rich layers (a thin layer and a thick layer) accompanied with $\mathrm{Ni}$ depletion are found. Between the two Cr-rich layers exists an $\mathrm{Sn}-\mathrm{Ni}$ matrix free of Ti clusters. It seems that the passage of the Ti clusters has been blocked by the thin Cr-rich layer. Figure 4(c) also shows that the Ni element dissolves heavily from Inconel 600 superalloy into the Sn10Ag4Ti filler metal, which may reinforce the weak Sn10Ag4Ti matrix. EDX analyses have been performed on the fracture surfaces of the specimens subjected to bending tests. These analyses reveal the brazed alumina/Inconel 600 joint fractures along the thinner Cr-rich layer on the superalloy side (Fig. 5), which are sufficient to confirm the thermal stress alleviation effect on the alumina wrought by the low solidifaction temperature of the Sn10Ag4Ti filler metal. In the previous case using an $\mathrm{Ag} 26 \mathrm{Cu}$ 8Ti filler metal, fracture was observed to occur to the ceramic in the brazed specimen.

For the joining of alumina ceramic with the UMCo-50 superalloy at $900{ }^{\circ} \mathrm{C}$ for $10 \mathrm{~min}$, Fig. 6(a) shows that both the alumina/Sn10Ag4Ti and Sn10Ag4Ti/UMCo-50 interfaces are stable, corresponding to a higher bonding strength of $57 \mathrm{MPa}$ compared with the brazements with Ag26Cu8Ti filler metal (43 MPa). The element titanium also clusters around inside the Sn10Ag4Ti filler metal. Adjacent to the UMCo-50 superalloy exists a broad band of $\mathrm{Sn}-\mathrm{Ag}-\mathrm{Co}$ matrix free of the Ti clusters, which is similar to that found in the alumina/Inconel 600 joint. From Fig. 6(c), the Co element of the UMCo-50 superalloy is also observed to dissolve into the Sn10Ag4Ti filler metal. The solid solution strengthening effect is also present in this case. As EDX analyses of the fracture surfaces (Fig. 7) of the alumina/UMCo-50 joints brazed with Sn10Ag4Ti filler metal indicate, the specimens fracture along the Sn10Ag4Ti/UMCo-50 

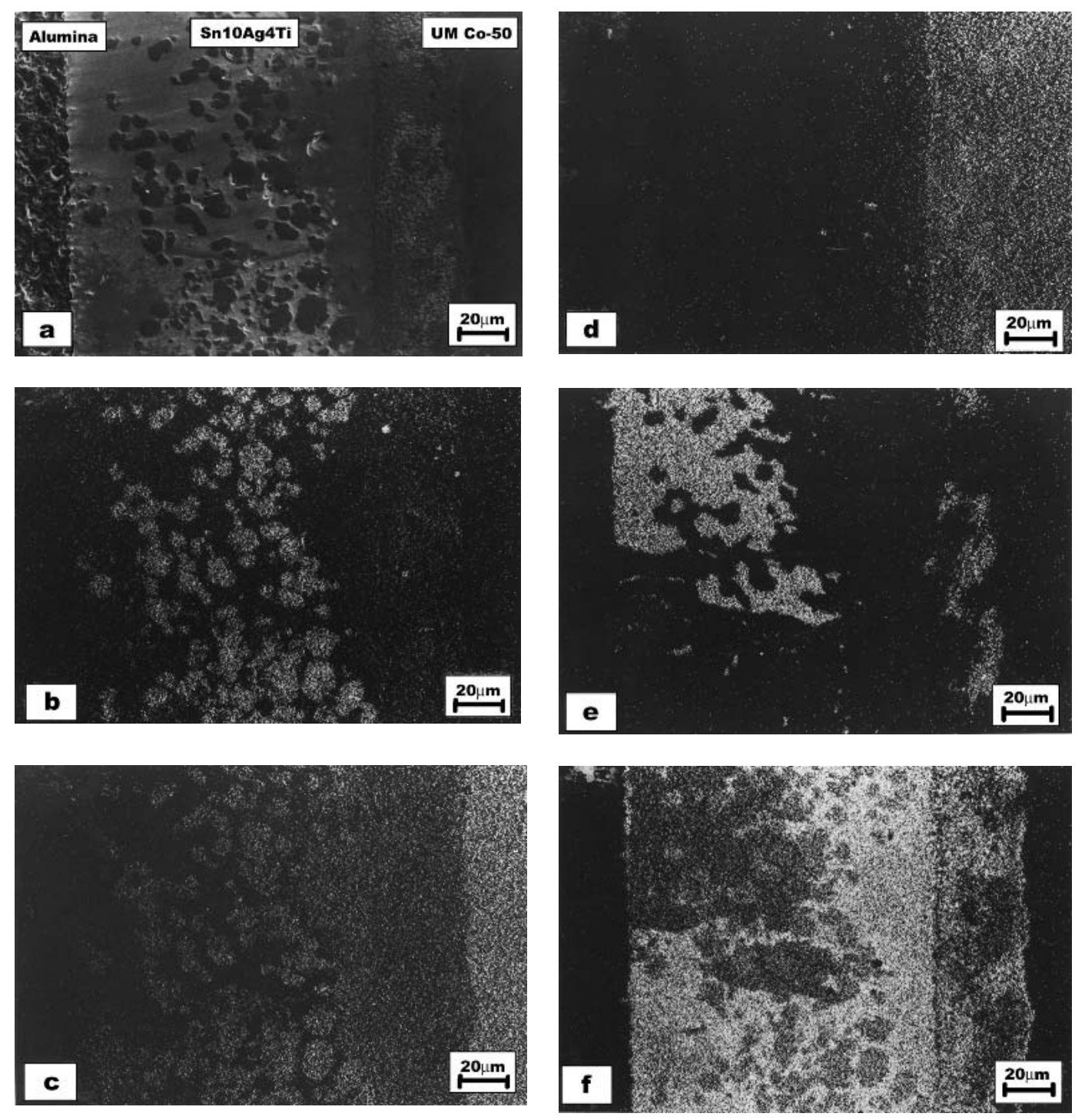

Fig. 6 Micrograph and EMPA analyses for the $\mathrm{Al}_{2} \mathrm{O}_{3} / \mathrm{Sn} 10 \mathrm{Ag} 4 \mathrm{Ti} / \mathrm{UMCo}=50$ joint after brazing at $900{ }^{\circ} \mathrm{C}$ for $10 \mathrm{~min}$. (a) interfacial microstructure; (b-f) elemental mappings for $\mathrm{Ti}, \mathrm{Co}, \mathrm{Cr}, \mathrm{Ag}$, and $\mathrm{Sn}$, respectively.

interface, unlike the previous case using the $\mathrm{Ag} 26 \mathrm{Cu} 8 \mathrm{Ti}$ filler metal where fracture would occur to the ceramic. ${ }^{[1]}$

\section{Conclusions}

For the brazing of alumina ceramics with Inconel 600 and UMCo-50 superalloys using an Ag26Cu8Ti filler metal, a previous study reported the bonding strengths of $53 \mathrm{MPa}$ and 43 $\mathrm{MPa}$, respectively. For specimens subjected to four-point bending tests, fracture was observed in the ceramic. The results indicated that great thermal stress occurred to the ceramic/ metal brazements. In the current study, a low-melting-point alloy Sn10Ag4Ti is used to solve this problem. Experimental results show that higher bonding strengths of $69 \mathrm{MPa}$ and 57 MPa can be achieved for the alumina/Inconel 600 and alumina/ UMCo-50 joints, respectively. In addition, the ceramic material in the bending test specimens has not been found to rupture as was observed in the previous case. It is obvious that the thermal stress in ceramic/metal joints can be effectively alleviated by using a low-melting-point filler metal Sn10Ag4Ti. During brazing, the Ni element of Inconel 600 and the Co element of UMCo-50 are found to dissolve into the Sn10Ag4Ti filler metal, which can also render the benefit of reinforcing the weak matrix of this Sn-based alloy.

\section{References}

1. H.W. Wu and T.H. Chuang: "Joining Alumina to Superalloys With Ag-Cu-Ti Active Filler Metals" in Proc. 4th Int. Conf. Joining Ceramics, Glass and Metal, Konigswinter, Germany, May 17-19, 1993, pp. $92-98$

2. O.M. Akselsen: "Advances in Brazing of Ceramics," J. Mater. Sci., 1992, 27, pp. 1989-2000.

3. P. Duhaj, P. Sebo, P. Svec, and D. Janickovic: “ Development and Characterisation of Ag-Cu-Ti Brazes Prepared With Planar Flow Casting," Mater. Sci. Eng. A, 1999, 271, pp. 181-87.

4. A.H. ElSawy and M.F. Fahmy: "Brazing of $\mathrm{Si}_{3} \mathrm{~N}_{4}$ Ceramic to Copper," J. Mater. Proc. Technol., 1998, 77, pp. 266-72. 

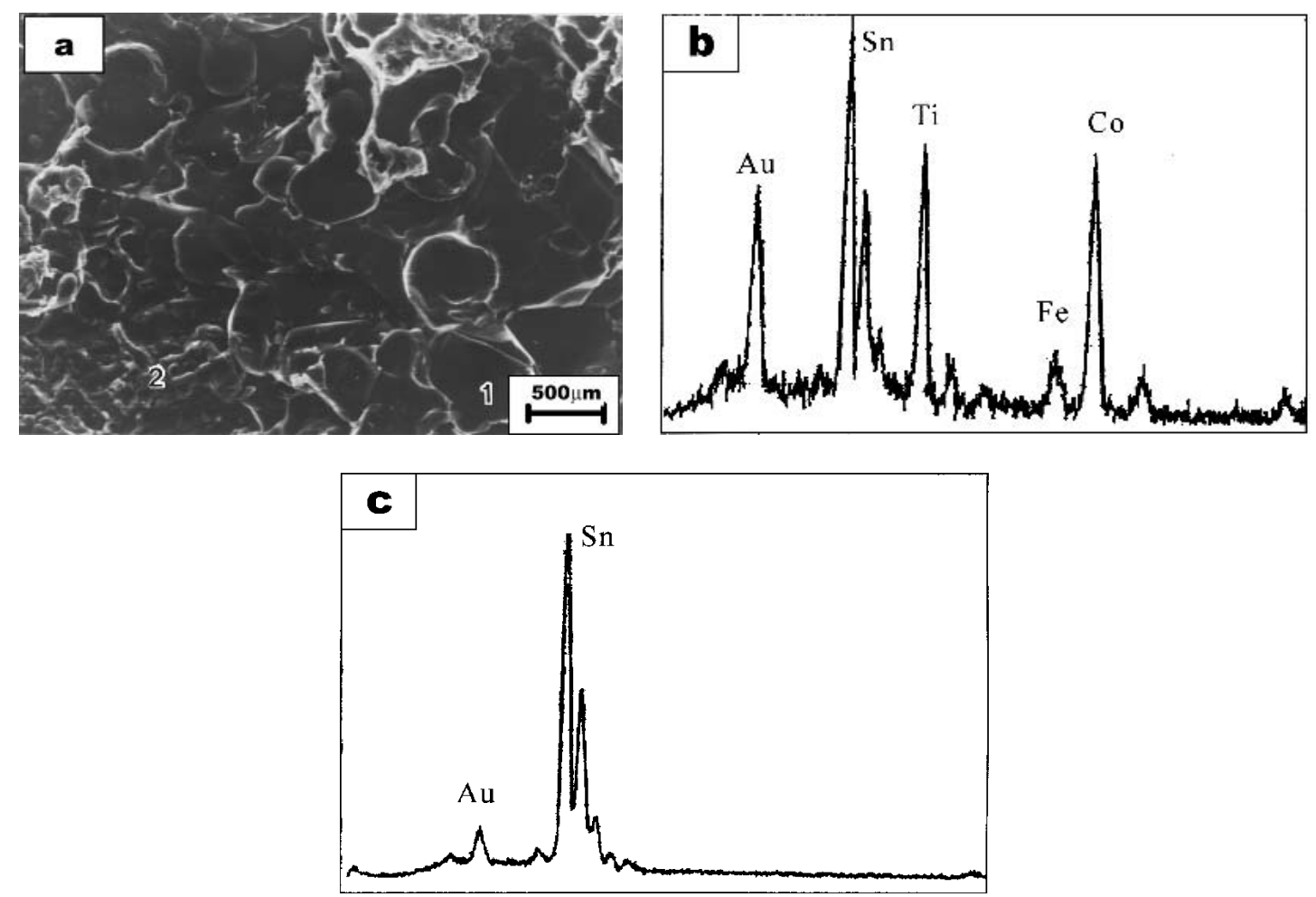

Fig. 7 EDX analysis on the fractured surface of the Alumina/UMCo-50 joint brazed with Sn10Ag4Ti filler metal. (a) fractography; (b) EDX peaks at point 1; (c) EDX peaks at point 2

5. W.B. Hanson, K.I. Ironside, and J.A. Ferine: "Active Metal Brazing of Zirconia," Acta Mater., 2000, 48, pp. 4673-76.

6. T. Yano, H. Suematsu, and T. Iseki: "High-Resolution Electron Microscop of a SiC/SiC Joint Brazed by a Ag-Cu-Ti Alloy," J. Mater. Sci., 1988, 23, pp. 3362-66.

7. J.K. Boadi, T. Yano, and T. Iseki: "Brazing of Pressureless-Sintered SiC Using Ag-Cu-Ti Alloy," J. Mater. Sci., 1987, 22, pp. 2431-34.
8. W. Weise, W. Malikowski, and W. Bohm: "Verbinden von Keramik mit Keramik oder Metall durch Aktivlöten unter Argon oder Vakuum," Firmenschrift Degussa Hanau AG, Hanau, Germany (in German).

9. Y.H. Chai, W.P. Weng, and T.H. Chuang: "Relationship Between Wettability and Interfacial Reaction for Sn10Ag4Ti on $\mathrm{Al}_{2} \mathrm{O}_{3}$ and $\mathrm{SiC}$ Substrates," Ceram. Int., 1998, 24, pp. 273-79. 